\title{
Pemberdayaan Masyarakat Melalui Inovasi Produk Asam Jawa Berbasis Ekonomi Lokal di Desa Nglopang Kecamatan Parang Kabupaten Magetan
}

\author{
Liana Vivin Wihartanti*, Dwi Nila Andriani, Adimas Rizky Saputra, \\ Nasiska Febri Chrisma Sari \\ Universitas PGRI Madiun \\ *Corresponding Email: lianavivin@unipma.ac.id
}

\begin{abstract}
ABSTRAK
Nglopang merupakan salah satu desa di Kabupaten Magetan yang memiliki potensi sumber daya alam yang melimpah. Objek dalam kegiatan Kuliah Kerja Nyata Tematik ini adalah pohon asam. Hasil dari pohon asam ini adalah pengolahan buah asam untuk menjadi produk olahan yang siap konsumsi. Kegiatan ini bertujuan untuk mengenalkan produk unggulan Desa Nglopang kepada masyarakat. Hasil dari kegiatan ini adalah terciptanya kerjasama yang baik dari berbagai pihak untuk menciptakan produk olahan gummy asam bersama masyarakat Desa Nglopang. Daging buah asam jawa tidak hanya sekedar di olah menjadi sirup asam dan manisan asam saja tetapi bisa di inovasi menjadi permen asam atau gummy asam yang mudah di olah dan juga bisa awet dalam jangka waktu lama tanpa bahan pengawet.
\end{abstract}

Kata kunci: Ekonomi Lokal, Asam Jawa, Gummy Asam.

\section{ABSTRACT}

Nglopang is one of the villages in Magetan Regency which has abundant natural resource potential. The object in this Thematic Real Work Lecture activity is the tamarind tree. The result of this tamarind tree is the processing of tamarind fruit into processed products that are ready for consumption. This activity aims to introduce the superior products of Nglopang Village to the community. The result of this activity is the creation of good cooperation from various parties to create processed sour gummy products with the people of Nglopang Village. The flesh of tamarind fruit is not only processed into tamarind syrup and sour sweets, but can be innovated into sour candy or sour gummy that is easy to process and can also last for a long time without preservatives.

Keywords: Local Economy, Tamarind, Gummy Asam.

\section{PENDAHULUAN}

PKK merupakan sebuah wadah yang bertujuan untuk memberdayakan keluarga untuk meningkatkan kesejahteraan menuju terwujudnya keluarga yang beriman dan bertaqwa kepada Tuhan Yang Maha Esa, berakhlak mulia dan berbudi luhur, sehat sejahtera, maju dan mandiri, kesetaraan dan keadilan gender serta kesadaran hukum dan lingkungan, demikian halnya program PKK yang ada di desa nglopang merupakan bagian dari pemberdayaan ibu-ibu yang berada di desa yang diarahkan untuk mempunyai usaha produktif yang memanfaatkan ataupun mengolah hasil produk lokal daerah sehingga dapat menyejahterakan keluarganya.

Nglopang merupakan salah satu desa di Kabupaten Magetan yang memiliki potensi sumber daya alam yang melimpah. Potensi sumber daya alam yang dimiliki desa nglopang meliputi padi, cabai, palawija, dan asam jawa. Asam jawa merupakan asset penting desa nglopang yang ingin di tonjolkan di daerah tersebut. komoditas utama yang menjadi icone dari desa nglopang adalah asam jawa, dimana asam jawa ini merupakan tanaman yang banyak tumbuh di desa Nglopang. Asam jawa 
atau dalam istilah latin Tamarindus indica mampu memberikan manfaat bagi kesehatan. Tamarindus indica atau asam jawa berfungsi sebagai aktioksidan yang terdapat pada buah, daun, biji (Pereira Paes Menezes et al, 2016). Pada suatu daerah yang memiliki bahan baku yang melimpah salah satunya asam jawa yang pada umumnya digunakan untuk campuran bumbu dan jamu bisa dikembangkan menjadi produk yang komersil. Salah satu daerah yang juga memanfaatkan asam jawa diolah menjadi produk yang bernilai jual adalah di Desa Bintang Mas Kabupaten Pontianak bersama-sama dengan masyarakat mengolah asam jawa menjadi produk kesehatan berupa sirup asam jawa yang bermanfaat untuk kesehatan (Dirhamsyah, M., \& Nurhaida, N. 2018). Hal ini merupakan aset juga bagi desa untuk menjadikan bahan lokal untuk dijadikan produk unggulan daerah. Persyaratan utama agar aset yang cukup berharga tersebut bisa menjadi sebuah komoditas daerah adalah dikelolanya potensi daerah tersebut dengan baik sesuai standar minimal industri pariwisata (Arifin \& Ariyanto, 2018). Potensi alam yang ada di desa Nglopang Kecamatan Parang Kabupaten Magetan ini jika dikelola dengan baik maka dapat menjadi salah satu sumber pendapatan masyarakat sekitar, dengan banyaknya pohon asam jawa yang tumbuh di sekitar lingkungan, masyarakat dapat memberikan inovasi untuk mengolah dan menghasilkan suatu produk yang baik untuk memudahkan mengkonsumsi asam jawa tersebut. Asam jawa yang merupakan jenis buah yang memiliki rasa masam dan biasa digunakan untuk campuran bumbu dalam banyak masakan Indonesia sebagai perasa atau penambah rasa asam dalam makanan. Menurut Harahap (2012) Pemberdayaan ekonomi masyarakat merupakan faktor-faktor produksi, penguatan penguasaan distribusi dan pemasaran, penguatan masyarakat untuk mendapatkan gaji/upah yang memadai, dan penguatan masyarakat untuk memperoleh informasi, pengetahuan dan ketrampilan, yang harus dilakukan secara multi aspek, baik dari aspek masyarakatnya sendiri, mapun aspek kebijakannya. Secara praktis upaya yang merupakan pengerahan sumber daya untuk mengembangkan potensi ekonomi rakyat ini diarahkan untuk meningkatkan produktivitas rakyat sehingga, baik sumber daya manusia maupun sumber daya alam di sekitar keberadaan rakyat, dapat ditingkatkan produktivitasnya. Dengan demikian, rakyat dan lingkungannya mampu secara partisipatif menghasilkan dan menumbuhkan nilai tambah ekonomis. pengembangan ekonomi lokal di Kecamatan Pagelaran memberikan dampak yang positif dimana dengan adanya pengembangan ekonomi lokal ini tercipta lapangan kerja baru sehingga meningkatkan perekonomian masyarakat sekitar. ( Susanti, 2013)

Adanya pohon asam yang terdapat di daerah Nglopang ini dapat menjadikan masyarakat lebih kreatif untuk mengolah dan memberikan inovasi terabaru dalam mengkonsumsi asam jawa sebagai permen asam atau biasa disebut dengan "Gummy Asam". Masyarakat telah dibimbing dan dengan dibekali kemampuan untuk memproduksi Gummy Asam dengan baik dan layak untuk dikonsumsi.

Berdasarkan uraian diatas, peneliti tertarik dengan gagasan utama berupa pemberdayaan masyarakat melalui inovasi produk asam jawa berbasis ekonomi lokal di desa Nglopang Kecamatan Parang Kabupaten Magetan agar dapat lebih dikenal masyarakat luas serta mendukung perluasan pemasaran asam jawa.

\section{METODE}

\section{Langkah yang digunakan dalam mengatasi permasalahan mitra}

Langkah awal yang dilaksanakan untuk mengatasi permasalahan mitra antara lain melalui: survei lokasi serta survei program merupakan strategi yang dilaksanakan untuk mengetahui sejauh mana program masyarakat dalam mengelola ekonomi lokal yang terdapat di daerah Nglopang, identifikasi potensi dan peluang mitra, analisis kebutuhan yang meliputi respon masyarakat mengenai produksi asam jawa yang di kelola oleh masyarakat desa Nglopang, pelaksanaan kegiatan dan evaluasi kegiatan. 
Tabel 1. Pelaksanaan Kegiatan

\begin{tabular}{|c|c|c|c|c|}
\hline No & Permasalahan & & Solusi yang ditawarkan & Tujuan \\
\hline 1 & $\begin{array}{l}\text { Terbatasnya pengetahuan } \\
\text { yang dimiliki oleh mitra } \\
\text { terkait aneka olahan } \\
\text { bahan pangan lokal }\end{array}$ & a. & $\begin{array}{l}\text { Pelatihan (ceramah, tanya } \\
\text { jawab, demonstrasi) tentang } \\
\text { pengetahuan bahan dan } \\
\text { teknik olah pengolahan } \\
\text { asam jawa dengan inovasi } \\
\text { yang dapat disukai oleh } \\
\text { semua kalangan. } \\
\text { Praktik pembuatan inovasi } \\
\text { olahan asam jawa menjadi } \\
\text { gummy asam. }\end{array}$ & $\begin{array}{l}\text { a. Memiliki pengetahuan } \\
\text { dan ketrampilan } \\
\text { memilih bahan dan } \\
\text { teknik olah pangan } \\
\text { lokal yang tepat } \\
\text { b. Bisa membuat aneka } \\
\text { olahan asam jawa lokal } \\
\text { dengan inovasi yang } \\
\text { lebih menarik. }\end{array}$ \\
\hline 2 & $\begin{array}{l}\text { Rendahnya pengetahuan } \\
\text { tentang proses produksi } \\
\text { dikarenakan keterbatasan } \\
\text { sarana }\end{array}$ & a. & $\begin{array}{l}\text { Praktek Cara Produksi } \\
\text { Pangan yang Baik } \\
\text { Diskusi dengan Mitra } \\
\text { Pendampingan/ }\end{array}$ & $\begin{array}{l}\text { Memiliki pengetahuan } \\
\text { dan ketrampilan cara } \\
\text { produksi pangan yang } \\
\text { baik pada pengolahan } \\
\text { pangan lokal }\end{array}$ \\
\hline 3 & $\begin{array}{l}\text { rendahnya pengetahuan } \\
\text { tentang pengemasan } \\
\text { dan pelabelan yang } \\
\text { menarik. }\end{array}$ & a. & $\begin{array}{l}\text { sosialisasi dan Praktik } \\
\text { packaging (pengemasan } \\
\text { dan pelabelan) }\end{array}$ & $\begin{array}{l}\text { Memiliki } \\
\text { pengetahuan dan } \\
\text { ketrampilan membuat } \\
\text { kemasan produk } \\
\text { yang menarik }\end{array}$ \\
\hline 4 & $\begin{array}{lr}\text { Masih rendahnya } \\
\text { pengetahuan } r \text { tentang } \\
\text { model pemasaran melalui } \\
\text { media internet. }\end{array}$ & a. & $\begin{array}{l}\text { sosialisasi Pelatihan } \\
\text { pembuatan promosi di } \\
\text { medsos seperti instagram }\end{array}$ & $\begin{array}{l}\text { Dapat menggunakan } \\
\text { internet sebagai media } \\
\text { pemasaran }\end{array}$ \\
\hline
\end{tabular}

\section{Metode pelaksanaan program}

Koordinasi dengan berbagai pihak antara lain adalah Kepala Desa, Sekertaris Desa, PKK, serta masyarakat setempat. Dalam kegiatan ini masyarakat serta mahasiswa dapat mengembangkan potensi alam yang ada dan membuat sesuatu inovasi serta membuat asam jawa mudah dikonsumsi. Pembuatan dan inovasi olahan asam jawa menjadi permen asam atau Gummy Asam dapat menjadi produk unggulan Desa Nglopang yang awalnya hanya di olah menjadi sirup asam, maka para mahasiswa bekerjasama dengan ibu-ibu PKK Desa Nglopang mengadakan program pelatihan pembuatan Gummy Asam.

Pelatihan diikuti oleh mahasiswa serta ibu-ibu PKK serta masyarakat yang ingin bergabung dalam pembuatan gummy asam. Dalam program tersebut dapat disampaikan bagaimana cara pengolahan yang baik dan pemaparan tentang apa saja alat-alat yang diperlukan, bahan yang dibutuhkan dalam pembuatan gummy asam ini tentu saja yang utama adalah asam jawa, gula pasir sebagai pemanis, agar-agar merk swallow dengan warna sesuai selera, Nutrijel rasa sesuai selera dan yang terakhir air untuk mencampur semua bahan yang siap untuk di masak.

Langkah pembuatan Gummy Asam tersebut yang pertama siapkan bahan dan alat yang dibutuhkan, setelah semua siap masukan semua bahan kedalam satu wadah dan aduk rata, kedua siapkan kompor dan letakkan wadah diatas kompor lalu didihkan menggunakan api kecil sampai mendidih setelah itu matikan apinya. Ketiga Aduk sampai uap panas menghilang kemudian tuangkan kedalam baki, setelah itu tunggu sampai jeli mengeras dan potong sesuai selera, setelah itu tata potongan jeli kedalam loyang lalu jemur di bawah sinar matahari dalam waktu 2-5 hari untuk menghasilkan jeli yang baik. berikut langkah pembuatan gummy asam. 

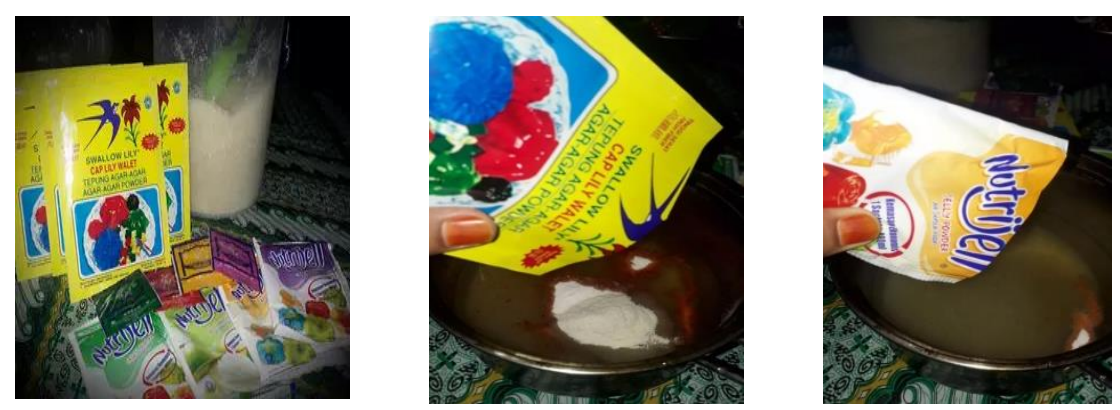

1. Menyiapkan bahan
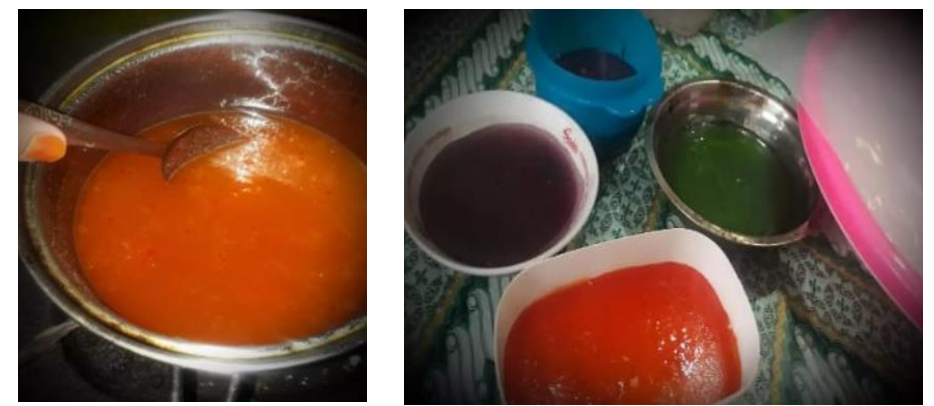

2. Mengolah Bahan

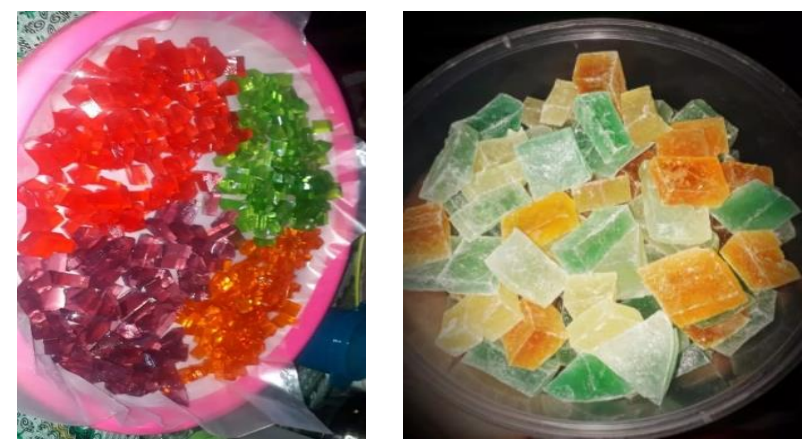

3. pengemasan produk

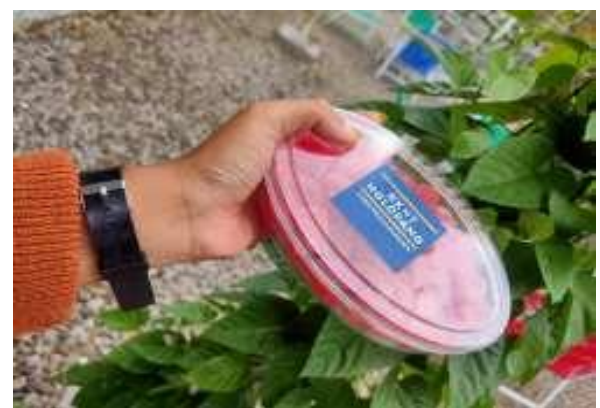

4. Produk Jadi

Gummy asam merupakan sebuah produk yang dikemas untuk memperkenalkan potensi desa dengan olahan yang menarik dan disuakai semua kalangan, sehingga ibu-ibu PKK dapat menelajutkan program ini sehingga diharapkan dapat meningkatkan kesejahteraan masyarakat desa Nglopang serta dapat digunakan sebagi cemilan untuk keluarga larena kandungan asam dan agar-agar aman dikonsumsi dan baik bagi pencernaan. Tidak hanya gummy asam saja beberapa produk olahan dapat di hasilkan dari olahan asam jawa ini sebagai contoh Jahe Kunyit Asam yang di proses menjadi serbuk untuk menjadikan minuman sehat yang dapat dikonsumsi sebagai tambah daya imun masyarakat Desa Nglopang. Dalam kegiatan ini juga meningkatkan kesadaran masyarakat tentang anugerah lingkungan yang telah diperoleh dari Tuhan untuk dijadikan sesuatu yang berharga jika mampu menjaga dan mengolah sesuatu yang awalnya biasa menjadi luar biasa. 


\section{PELAKSANAAN DAN PEMBAHASAN `}

Sosialisasi kegiatan kepada mitra kelompok wanita tani dilaksanakan pada hari Jum'at tanggal 14 januari 2021, pukul 15.30-17.00, bertempat di rumah Ibu sugiharto ( Kepala Desa Nglopang) Hasil dari kegiatan yang telah dilaksanakan adalah terciptanya kerjasama yang baik dengan berbagai pihak antara lain adalah Kepala Desa, Sekertaris Desa, PKK, dan masayarakat setempat. Dengan adanya kerjasama tersebut dapat tercipta inovasi olahan asam jawa berupa gummy asam buatan masyarakat Desa Nglopang, Kecamatan Parang, Kabupaten Magetan. pemberian materi diawali dengan penjelasan dan demostrasi cara pembuatan produk, kemudian kepada peserta dipersilahkan untuk melakukan sendiri cara membuat produk mulai dari persiapan sampai produk jadi dan siap dikonsumsi. Hasil produk yang sudah jadi kemudian dievaluasi bersama-sama sehingga peserta mengetahui kekurangan dan kelebihan produk yang sudah dibuat. Dengan demikian, mereka juga memperoleh pengetahuan tentang karakteristik masing-masing produk. Kegiatan pelatihan praktik pembuatan gummy asam terlaksana dengan lancar sesuai dengan jadwal yang telah disusun. Adanya atusiame peserta dalam mengikuti praktik pembuatan gummy asam, yaitu peserta mengikuti pelatihan dengan penuh semangat dari tahapan-tahapan selama kegiatan berlangsung.

Evaluasi pelatihan teori di- lakukan untuk mengetahui pemahaman peserta akan manfaat olahan pangan lokal, jenis-jenis olahan asam jawa lokal maupun potensinya se- bagai bahan makanan layak jual. Evaluasi dilakukan dengan memberikan beberapa pertanyaan kepada peserta pelatihan setelah materi teori diberikan. Dari segi teori, kriteria keberhasilannya adalah peserta pe- latihan mampu menjawab dengan benar pertanyaan yang diberikan minimal $80 \%$. Evaluasi pelatihan praktek dilakukan untuk mengetahui kemampuan peserta dalam mengolah olahan asam lokal menjadi aneka produk yang bisa di nikmati oleh semua kalangan.

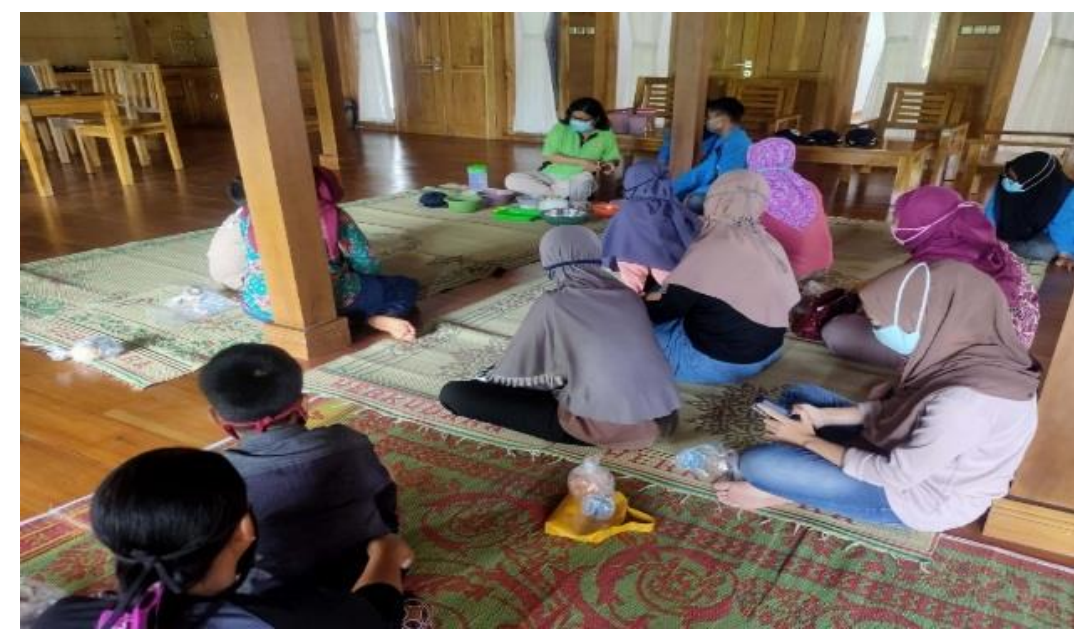

Gambar 1. Foto kegiatan Pratik membuat Gummy asam

\section{SIMPULAN}

\section{Simpulan}

Berdasarkan hasil kegiatan, pengamatan, maupun pelaksanaan kegiatan di Desa Nglopang Kecamatan Parang Kabupaten Magetan dapat disimpulkan bahwa Daging buah asam jawa tidak hanya sekedar di olah menjadi sirup asam dan manisan asam saja tetapi bisa di inovasi menjadi permen asam atau gummy asam yang mudah di olah dan juga bisa awet dalam jangka waktu lama tanpa bahan pengawet. Dengan adanya program tersebut dapat menambah pengetahuan bagi mahasiswa serta masyarakat setempat untuk mengetahui pentingnya mendukung perkembangan ekonomi lokal yang sudah ada. Dari program pelatihan menjadikan masyarakat terampil untuk mengkreasikan ide selanjutnya. Pengembangan ekonomi lokal ini tentu memberikan dampak yang positif khususnya bagi masyarakat sekitar. 


\section{Saran}

Saran yang dapat disampaikan untuk keberlanjutan kegiatan Pembuatan media sosial dan website sebagai pendukung produk gummy asam untuk dipasarkan secara online sehingga dapat membantu perekonomian masyarakat desa nglopang. Pembangunan tempat produksi gummy asam di daerah desa Nglopang untuk mendukung perkembangan ekonomi Desa Nglopang yang berbasis ekonomi lokal. Membuka lowongan pekerjaan untuk mayarakat yang belum memiliki pekerjaan agar bisa mengurangi tingkat pengangguran di deda nglopang.

\section{UCAPAN TERIMAKASIH}

Kegiatan Pengabdian Masyarakat ini dapat berjalan lancar karena mendapat bantuan dan dukungan dari berbagai pihak. Oleh karena itu kami ucapkan terima kasih kepada: 1) Universitas PGRI Madiun yang sudah memberikan ijin, sarana dan fasilitas kepada kami, 2) Ketua LPPM Universitas PGRI Madiun, 3) Semua mahasiswa KKN Universitas PGRI Madiun Kelompok 17 desa Nglopang Kecamatan Parang Kabupaten Magetan yang meliputi : Anilailatul Muzayanah, Ardya Citra Yurindha, Hilda Apriliana, Galih Nova Andrian, Diarti Anggita Putri, Nora Erfianingtyas, Rama Hadi Nanda Kusuma, Aji Sasmito, Pia Ardhya Garini, Nasiska Febri Chrisma Sari, Octavia Indina Putri, Amalia Nurdianata, Yeni Ikawati, Bagus Tetuko Priyambodo, Fedyta Setiatama Nugraha, Banang Mufti Harnansyah, Sad Omega Kencanawaty 4) Perangkat Desa Nglopang Kecamatan Parang Kabupaten Magetan yang memberikan tempat untuk kami dalam menimba ilmu dan memberikan kami banyak pengalaman.

\section{DAFTAR PUSTAKA}

Dirhamsyah, M., \& Nurhaida, N. (2018). Pembuatan sirup asam jawa (Tamarindus Indica L.) sebagai salah satu usaha diversifikasi pangan untuk minuman kesehatan di desa bintang mas kecamatan rasau jaya kabupaten kubu raya. Jurnal Pengabdi, 1(1), 1-6.

Harahap, E. F. (2012). Pemberdayaan Masyarakat Dalam Bidang Ekonomi Untuk Mewujudkan Ekonomi Nasional Yang Tangguh Dan Mandiri. Jurnal Manajemen dan Kewirausahaan, 3(2), 78-96.

Kurniyati, Y., Rahmawati, F., \& Suryati, P. (2014). Optimalisasi Pemanfaatan dan Diversifikasi Olahan Pangan Lokal sebagai Upaya Pemberdayaan Masyarakat. INOTEKS, 18(1).

Menezes, A. P. P., Trevisan, S. C. C., Barbalho, S. M., \& Guiguer, E. L. (2016). Tamarindus indica L. A plant with multiple medicinal purposes. Journal of Pharmacognosy and Phytochemistry, $5(3), 50$.

Susanti, E. A. (2013). Pengembangan ekonomi lokal dalam sektor pertanian (studi pada Kecamatan Pagelaran Kabupaten Malang). Jurnal Administrasi Publik, 1(4), 31-40. 